\title{
Ambulatory extracorporeal membrane oxygenation: A new approach for bridge-to-lung transplantation
}

\author{
Jose P. Garcia, MD, ${ }^{\mathrm{a}}$ Aldo Iacono, MD, ${ }^{\mathrm{b}}$ Zachary N. Kon, MD, ${ }^{\mathrm{a}}$ and Bartley P. Griffith, MD, ${ }^{\mathrm{a}}$ Baltimore, Md
}

Extracorporeal membrane oxygenation (ECMO) for severe respiratory failure can be used to maintain adequate gas exchange but precludes ambulation and may lead to further deconditioning. We present a case of ambulatory ECMO for severe respiratory failure using a dual-lumen single cannula system.

\footnotetext{
From the Divisions of Cardiac Surgery ${ }^{\mathrm{a}}$ and Pulmonary Medicine, ${ }^{\mathrm{b}}$ University of Maryland School of Medicine, Baltimore, Md.

Disclosures: None.

Received for publication Dec 7, 2009; accepted for publication Dec 9, 2009; available ahead of print March 10, 2010.

Address for reprints: Jose P. Garcia, MD, Assistant Professor of Surgery, Associate Director of Heart and Lung Transplantation, Division of Cardiac Surgery, University of Maryland School of Medicine, 22 S Greene St N4W94, Baltimore, MD 21201 (E-mail: jgarcai@smail.umaryland.edu).

J Thorac Cardiovasc Surg 2010;139:e137-9

$0022-5223 / \$ 36.00$

Copyright (c) 2010 by The American Association for Thoracic Surgery doi:10.1016/j.jtcvs.2009.12.021
}

\section{CLINICAL SUMMARY}

A 49-year-old man with chronic carbon dioxide retention and elevated serum bicarbonate levels awaiting lung transplantation for severe chronic obstructive pulmonary disease (COPD) had respiratory failure owing to an acute COPD exacerbation. He was admitted to the medical intensive care unit and began receiving mechanical ventilation. Arterial blood

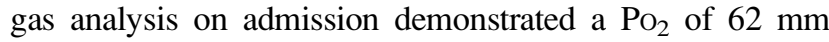
$\mathrm{Hg}$ and $\mathrm{PCO}_{2}$ greater than $100 \mathrm{~mm} \mathrm{Hg}$. Despite aggressive treatment with steroids, inhaled bronchodilators, antibiotics, sildenafil, inhaled nitric oxide, and theophylline for 2 weeks, the patient remained ventilator dependent. He was therefore advanced to ambulatory ECMO to alleviate the need for mechanical ventilation and allow aggressive rehabilitation.

Under general anesthesia in the cardiac operating theater, the internal jugular vein was located with ultrasound and marked. A small incision was made over the vein and dissection was carried down to the internal jugular vein. To allow a more comfortable lie of the proximal dual-lumen catheter

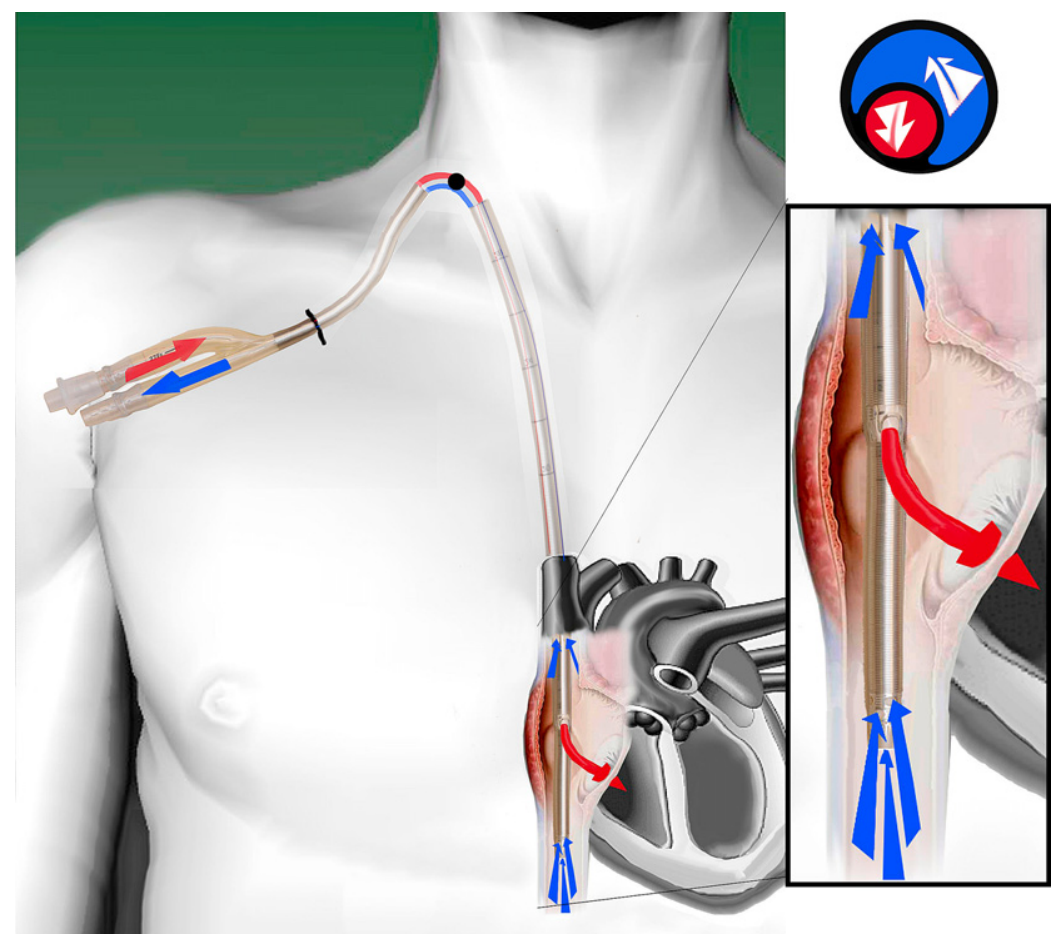

FIGURE 1. Insertion of the dual-lumen cannula into the internal jugular vein by tunneling from the right subclavicular chest. Note the subtle curve of the tunneled cannula. Inflow to the ECMO circuit is from the tip of the cannula located in the inferior vena cava and fenestrations in the mid-cannula at the superior vena cava-right atrial junction. Outflow between these 2 points is directed at the tricuspid valve. 


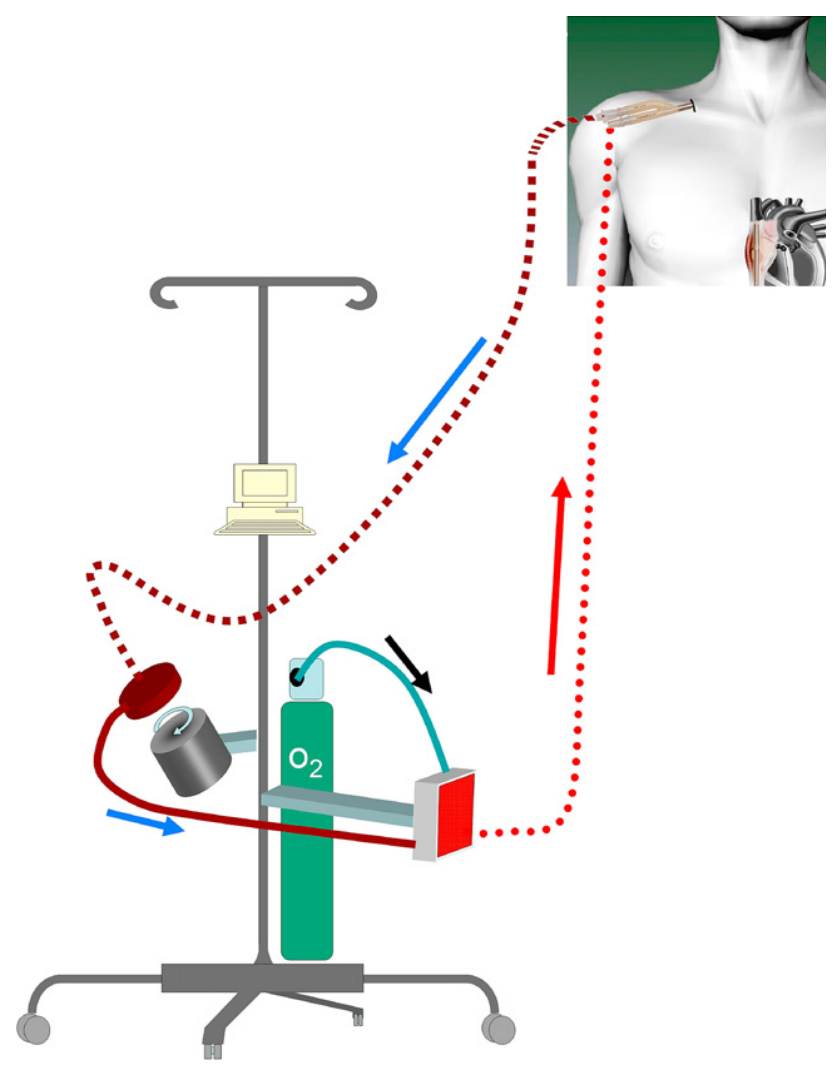

FIGURE 2. Ambulatory ECMO circuit.

and its inflow and outflow tubing attachments, we created an 8-cm subcutaneous tunnel anterior to the clavicle and tunneled the catheter in the subcutaneous plane to exit infraclavicularly. Using a modified Seldinger technique with transesophageal echocardiographic guidance, we positioned an introducer wire with the tip extending $2 \mathrm{~cm}$ into the inferior vena cava and the tract was serially dilated. A 23F Avalon cannula (Avalon Laboratories, LLC, Rancho Dominguez, Calif) was positioned over the wire under transesophageal echocardiographic guidance (Figure 1) and the cannula was connected to the ECMO circuit. The pump (Levitronix Centrimag, Boston, Mass), oxygenator (Maquet Quadrox Cardiovascular LLC, San Jose, Calif), and oxygen tank were attached to a wheeled intravenous pole to facilitate patient mobility (Figure 2). Flows in excess of $2 \mathrm{~L}$ at $3000 \mathrm{RPM}$ were achieved with a negative pressure of approximately $60 \mathrm{~mm} \mathrm{Hg}$. The incisions were then closed and the cannula secured. After the procedure, the patient's arterial $\mathrm{PCO}_{2}$ decreased to $40 \mathrm{~mm} \mathrm{Hg}$ and the patient maintained an average arterial $\mathrm{Po}_{2}$ greater than $100 \mathrm{~mm} \mathrm{Hg}$. Mechanical ventilation was weaned with a tracheostomy collar within 24 hours, and the patient began physical rehabilitation on postoperative day 1 . He was able to ambulate throughout the hospital, and use a treadmill and exercise bike. Table I shows average daily carbon dioxide extraction and oxygen transfer for the first 10 postoperative days. On postoperative day 19, the patient
TABLE 1. Daily ECMO gas exchange

\begin{tabular}{cccc}
\hline POD & Flow (L/min) & $\mathbf{C O}_{\mathbf{2}}$ removal $(\mathbf{m L} / \mathbf{m i n})$ & $\mathbf{O}_{\mathbf{2}}$ transfer $(\mathbf{m L} / \mathbf{m i n})$ \\
\hline 2 & 2.4 & 185 & 90 \\
3 & 2.5 & 175 & 79 \\
4 & 2.5 & 175 & 74 \\
5 & 2.5 & 185 & 100 \\
6 & 2.5 & 233 & 109 \\
7 & 2.5 & 143 & 97 \\
8 & 2.5 & 279 & 70 \\
9 & 2.5 & 250 & 92 \\
10 & 2.4 & 233 & 77 \\
\hline
\end{tabular}

ECMO, Extracoporeal membrane oxygenation; $P O D$, postoperative day.

underwent uneventful double lung transplantation and was discharged home 20 days later. He remains well 7 months after transplantation.

\section{DISCUSSION}

Severe respiratory failure is a complex entity that remains a management challenge. Successful therapies include early institution of mechanical ventilation with positive endexpiratory pressure and permissive hypercapnia, complex fluid regimens, and pulmonary vasodilators. ${ }^{1,2}$ Despite these advances, a significant number of patients with respiratory failure continue to have insufficient pulmonary gas exchange. ECMO provides efficient oxygenation and respiration in the setting of severe respiratory failure, ${ }^{3}$ but it restricts patient mobility, leading to deconditioning that further prolongs the time to recovery. Conventional ECMO, whether venovenous or venoarterial, requires cannulation of at least 1 femoral vessel, necessitating patient immobilization. A duallumen single cannula system enables venovenous ECMO via cannulation of only the internal jugular vein, allowing the patient to ambulate and rehabilitate, thus decreasing the risk of ventilator-associated pneumonias and deconditioning.

The case we describe is the first published report of a patient who was ECMO dependent but able to ambulate freely without mechanical ventilation. Ambulation and aggressive rehabilitation occurred with adequate gas exchange. This is particularly noteworthy because the etiology of his respiratory failure was COPD and patients with this condition are known to be more difficult to wean from mechanical ventilation. ${ }^{4,5}$ Although this patient was bridged to transplantation, the success of this patient may warrant further study of the utility of ambulatory ECMO for lung healing.

The authors thank Ivan George at the University of Maryland School of Medicine for creating Figures 1 and 2.

\section{References}

1. Amato MBP, Barbas CSV, Medeiros DM, Magaldi RB, Schettino GP, LorenziFilho G, et al. Effect of a protective-ventilation strategy on mortality in the acute respiratory distress syndrome. N Engl J Med. 1998;338:347-54.

2. Rossaint R, Falke KJ, López F, Slama K, Pison U, Zapol WM. Inhaled nitric oxide for the adult respiratory distress syndrome. N Engl J Med. 1993;328:399-405. 
3. Lewandowski K. Extracorporeal membrane oxygenation for severe acute respiratory failure. Crit Care. 2000;4:156-68.

4. Petrof BJ, Legare M, Goldberg P, Milic-Emili J, Gottfried SB. Continuous positive airway pressure reduces work of breathing and dyspnea during weaning from mechanical ventilation in severe chronic obstructive pulmonary disease. Am Rev Respir Dis. 1990;141:281-9.

5. Yang KL, Tobin MJ. A prospective study of indexes predicting the outcome of trials of weaning from mechanical ventilation. N Engl J Med. 1991;324:1445-50.

\title{
A case of Sjögren's syndrome leading to mitral and aortic valve replacement
}

\author{
Kevin Bridge, MD, MSPH, and Robert Saeid Farivar, MD, PhD, Iowa City, Iowa
}

A 62-year-old woman presented with dyspnea on exertion, and an echocardiogram demonstrated an ejection fraction of $55 \%$ to $60 \%$, severe mitral regurgitation, and moderate aortic regurgitation. The patient had rheumatic disease as a child, and her valve failure was presumed to be due to rheumatic disease sequelae. She previously had an axillary lymph node biopsy for adenopathy at an outside hospital and was thought to have Castleman's disease. At the University of Iowa Heart and Vascular Center, she underwent aortic and mitral valve replacement through a full sternotomy and bicaval cannulation. The aortic valve was replaced with a 21-mm Magna ThermaFix Edwards bovine pericardial valve (Edward Lifesciences, Irvine, Calif). The mitral valve was replaced with a 29-mm St Jude Epic porcine valve (St Jude Medical Inc, St Paul, Minn). Intraoperatively, the pericardium was found to be inflamed and adherent to the aorta and right ventricle. The native aortic valve was trileaflet, and both valves were rubbery in consistency with significant nodules present. The leaflets were friable. No calcification was found on the mitral annulus. The mitral valve was not repairable.

The gross pathology showed tan white nodules, $0.3 \mathrm{~cm}$ in the greatest dimensions, with spiculated appendages on the surface of the valves. The microscopic pathology demonstrated fibroelastic tissue with focal palisading and noncaseating granulomatous inflammation with central necrosis (Figure 1). Postoperative recovery was uneventful. The patient underwent multiple serologic tests that suggested a diagnosis of Sjögren's syndrome (Table 1), which was

\footnotetext{
From the Department of Cardiothoracic Surgery, University of Iowa Hospitals and Clinics, Carver College of Medicine, University of Iowa Heart and Vascular Center, Iowa City, Iowa.

Disclosures: None.

Received for publication Sept 13, 2009; accepted for publication Nov 28, 2009; available ahead of print Feb 22, 2010.

Address for reprints: Robert Saeid Farivar, MD, PhD, University of Iowa, Cardiothoracic Surgery, 200 Hawkins Dr, SE517GH, Iowa City, IA 52242-1062 (E-mail: robert-farivar@Uiowa.edu).

J Thorac Cardiovasc Surg 2010;139:e139-40

0022-5223/\$0.00

Published by Elsevier Inc. on behalf of The American Association for Thoracic Surgery

doi:10.1016/j.jtcvs.2009.11.068
}

confirmed with a positive Schirmer's test and a labial salivary gland biopsy.

\section{DISCUSSION}

Sjögren's syndrome was first identified in 1933 by Dr Henrik Sjögren and is a chronic autoimmune disorder with lymphocytic infiltration of the exocrine glands. Sjögren's syndrome manifests with sicca symptoms, including xerophthalmia and xerostomia. This disease primarily affects women, and most cases are diagnosed during the middleage years. Sjögren's syndrome occurring without any other manifestation of other autoimmune diseases has been labeled as primary Sjögren's syndrome. Secondary Sjögren's

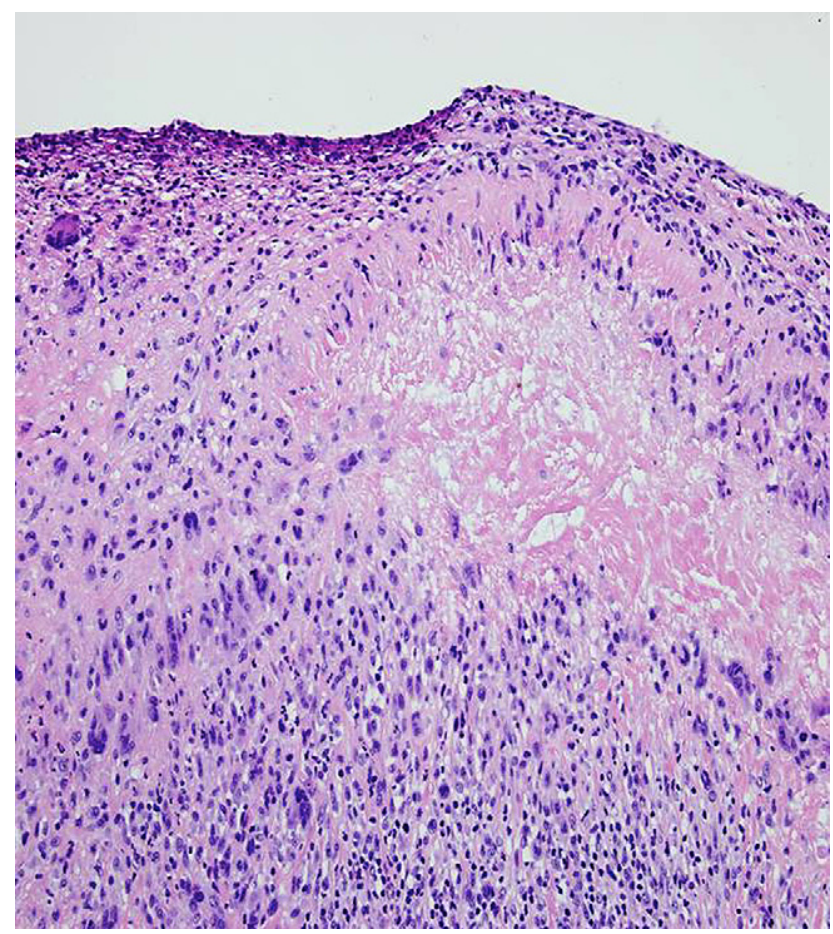

FIGURE 1. Mitral valve leaflet pathology demonstrating palisading and granulomatous inflammation, $200 \times$. 